\title{
VARIABILIDADE ESPACIAL DA CHUVA NA MICRORREGIÃO GEOGRÁFICA DE CAMPO MOURÃO (PR) ENTRE 1976-2016
}

\section{RAINFALL SPATIAL VARIABILITY IN THE CAMPO MOURÃO GEOGRAPHICAL MICRORREGION (PARANÁ STATE) BETWEEN 1976-2016}

\author{
Jeremias Alecio Leperes de MARINS ${ }^{1}$ \\ Leila LIMBERGER ${ }^{2}$
}

\begin{abstract}
Resumo: Estudos de variabilidade climática são importantes pois ajudam a compreender as excepcionalidades meteorológicas, que podem afetar a sociedade. Visando contribuir nesse campo científico, o presente artigo demonstra a variabilidade pluviométrica na Microrregião Geográfica de Campo Mourão (MRCM). Foram analisados dados de 24 postos pluviométricos, resultando na definição de duas unidades espaciais homogêneas quanto à variabilidade da chuva, denominadas de Norte da MRCM (NMRCM) e Sul da MRCM (SMRCM). Ao analisar os dados, verifica-se que na SMRCM os volumes de precipitação são maiores do que os registrados na NMRCM, tanto mensalmente como sazonal e anualmente. Apesar de, estatisticamente, não haver diferença entre as médias das duas unidades espaciais, foi possível notar que esta diferenciação de maior precipitação no Sul tende a ser um padrão, também identificado em outras pesquisas. Foram analisadas informações de altitude e latitude, comparadas com a chuva, e verificou-se que ambas auxiliam na compreensão do padrão espacial da chuva, apesar de o valor de correlação linear entre chuva e latitude ser maior. Na parte Sul, onde ocorrem as maiores altitudes, estas favorecem maior convecção de ar, e, também, há maior precipitação em virtude dos sistemas atmosféricos que ali atuam. Esse resultado reforça o caráter de transição climática identificado na MRCM.
\end{abstract}

Palavras-Chaves: Unidade espaciais homogêneas; Fator latitude; Fator altitude.

\begin{abstract}
Studies of climate variability are important because they report the meteorological exceptionalities that can affect the society. Thus, this paper demonstrates the pluviometric variability in the Geographic Microregion of Campo Mourão (MRCM). Data from 24 pluviometric stations were analyzed, resulting in the definition of two homogeneous rainfall space units, being named Northern MRCM (NMRCM) and Southern MRCM (SMRCM). In analyzing the data, it is verified that the rainfall is higher in the SMRCM than in the NMRCM, monthly, seasonally and annually. Although there is no statistically difference between the two space unites rainfall means, it was possible to note that this differentiation of greater precipitation in the South tends to be a pattern, also identified in other studies. Were analyzes latitude and altitude information, compared to rainfall, it was verified that both assist in understanding the spatial pattern in rainfall, although the linear correlation value between rainfall and latitude was higher. In the South, where the highest altitudes occur, there are greater air convection, and, also, there is greater precipitation due to the atmospheric systems that work there. This result reinforces the climate transition character identified in the MRCM.
\end{abstract}

Keywords: Homogeneous space units; Latitude factor; Altitude factor.

\footnotetext{
${ }^{1}$ Mestre pelo Programa de Pós-graduação em Geografia da Universidade Estadual do Oeste do Paraná/Marechal Cândido Rondon, PR. E-mail: jaleciomarins@ @otmail.com.

${ }^{2}$ Docente do Programa de Pós-graduação em Geografia da Universidade Estadual do Oeste do Paraná/Marechal Cândido Rondon, PR. E-mail: leila.limberger@unioeste.com.
} 


\section{Introdução}

O clima é a manifestação da conjugação entre a biosfera, criosfera, hidrosfera, geosfera e atmosfera, o que é conhecido como Sistema Superfície-Atmosfera (AYOADE, 1998; MENDONÇA e DANNI-OLIVEIRA, 2007; BARRY e CHORLEY, 2013). É também entendido como a sintetização das características gerais da dinâmica da atmosfera em um determinado lugar por um longo período de tempo. Ao mesmo tempo em que há essa tentativa de sistematização (aproximação à média) percebe-se que é fundamental estudar a variabilidade desse clima para entender seu comportamento ao longo do tempo.

A variabilidade climática pode ser compreendida em diferentes escalas temporais e espaciais. A variabilidade temporal é entendida como "a maneira pela qual os parâmetros climáticos variam no interior de um determinado período de registro" (TAVARES, 2001, p. 15), enquanto a variabilidade espacial é a compreensão de como os parâmetros climáticos variam em uma determinada área, podendo ocorrer nos níveis interativos de macro, meso e micro (MENDONÇA e DANNI-OLIVEIRA, 2007).

Estudos sobre variabilidade climática demonstram as atipicidades climáticas e são essas as que atingem a sociedade (ELY, 2006). Neste aspecto, Tavares (2001) afirma que compreender a variabilidade climática auxilia na capacidade de adaptação das sociedades, sendo isso possível através de estudos e ações de caracterização e planejamento.

A maior parte dos estudos nesta temática são sobre variabilidade temporal, especialmente em sua associação com anomalias da Temperatura da Superfície dos Mares (TSM) ou índices oceânicos. Para entender as causas da variabilidade climática no Paraná, Nascimento Junior (2013) a investigou, em sua relação com a Oscilação Decenal do Pacífico (ODP), utilizando a análise da tipologia pluviométrica. Para o autor, essa relação se mostrou estatisticamente fraca, já que é difícil encontrar associação estatística entre um elemento que varia muito (a chuva) com um modo de variabilidade de baixa a baixíssima frequência, que é a ODP. A partir desses resultados o autor relacionou a variabilidade pluviométrica com a produtividade agrícola e verificou valores positivos de correlação entre o índice da ODP e a cultura do arroz e valores negativos de correlação linear para as culturas de soja, milho, canade-açúcar e feijão, porém, não significativo para todas as regiões do Estado

Souza (2006) compara a variabilidade de precipitação no Paraná e a anomalia de TSM do oceano Pacífico entre 1972 a 2002, utilizando dados de 43 estações pluviométricas e analisando a tipologia da chuva. Verificou que a relação da chuva no Paraná com El 
Niño/Oscilação Sul (ENOS) mostra que anos de El Niño (La Niña) há aumento (redução) de chuva. Todavia, estas anomalias de precipitação se diferem por regiões. Esse resultado sobre efeito dos eventos ENOS na chuva no Paraná também foi identificado por outros trabalhos.

Diversas pesquisas já abordaram os efeitos dos eventos ENOS na variabilidade temporal da chuva na região sul do Brasil ou no estado do Paraná, especificamente (NERY, VARGAS e MARTINS, 1997; ALMEIDA, 2000; GRIMM, 2003; PRELA, 2004; BALDO, 2006; SOUZA, 2006; NASCIMENTO JR., 2013; MARINS e LIMBERGER, 2018; MINAKI e MONTANHER, 2019)

Assume-se que há o efeito na não-linearidade quanto aos efeitos dos ENOS, sendo que “cada evento ENOS tem sua própria característica” (AMBRIZZI, 2003), dependendo também do comportamento da TSM em outras áreas oceânicas. No entanto, entende-se, a partir dos resultados das pesquisas já citadas, que os fenômenos de El Niño forte e muito forte contribuem para o aumento das chuvas na região, enquanto as La Niñas contribuem para sua redução, mesmo que essa associação seja mais fraca.

Assumindo os conhecimentos prévios sobre a variabilidade temporal, o objetivo principal do presente artigo é entender a variabilidade espacial da chuva na Microrregião Geográfica de Campo Mourão (MRCM) para o período de 1976 a 2016, analisando fatores que se relacionam com o gradiente pluviométrico, como a altitude e a latitude.

A pluviosidade, bem como, sua variabilidade espacial, é resultado da sua ligação com a passagem de sistema transicionais de escala sinótica, que atuam na baixa e média troposfera e a interação com a superfície. Sendo assim, é importante analisar a distribuição espacial das chuvas, identificando áreas distintas pluviometricamente.

A compreensão da variabilidade pluviométrica na área do estudo é fundamental, já que esta é uma área de atividade econômica baseada na agricultura comercial (MASSOQUIM, 2010), que depende em grande parte da disponibilidade hídrica, apesar do avanço técnico aplicado na agricultura nas últimas décadas. Períodos prologados de estiagens conhecidos como veranicos tem trazido impedimentos para um maior rendimento na agricultura, assim como os excessos pluviométricos (períodos prolongados de chuva), que atingem a área principalmente durante a fase da colheita, ou causando erosão por manejos inadequados durante o plantio, sendo o não plantio direto.

Além disso, salienta-se a localização da MRCM em uma área de transição climática (MASSOQUIM, 2010; BORSATO e MENDONÇA, 2013), o que faz com que a área receba a atuação de diversos sistemas transicionais de escala sinótica, que atuam na baixa e média 
troposfera, tais como frentes frias, ciclones extratropicais, sistemas convectivos de mesoescala (SCMs), linhas de instabilidades pré-frontal e bloqueios atmosféricos (REBOITA et al., 2010; REBOITA et al., 2012), o que complexifica sua característica climática.

Na sequência do artigo são apresentados os procedimentos metodológicos utilizados, bem como, a localização da área de estudos. No item Resultados e Discussão são apresentados os resultados da análise de Cluster, que identificou unidades espaciais homogêneas de variabilidade pluviométrica, a caracterização climática das duas unidades espaciais e a análise dos efeitos de altitude e latitude nos valores da precipitação para as duas unidades espaciais. Ao final, são apresentadas as conclusões do artigo.

\section{Procedimentos metodológicos e localização da área de estudo}

A área do estudo é a Microrregião Geografia de Campo Mourão - MRCM, localizada na mesorregião Centro Ocidental Paranaense, segundo as coordenadas Latitude entre $23^{\circ} 33^{\prime}$ 9"S a $24^{\circ} 43^{\prime} 47^{\prime \prime} \mathrm{S}$, e Longitude $51^{\circ} 53$ ' 22 "W a 52 46' $53^{\circ}$ " W; a mesma é formada por quatorze municípios (Figura 1), compreendendo uma área de 7.069,66 quilômetros quadrados. Sua população estimada para 2018 era de 221.559 habitantes (IBGE, 2018), sendo que o munícipio mais populoso é Campo Mourão, tido como cidade sede desta microrregião. É considerada uma região de colonização recente, a partir da década de 1940, em que, exceto um município, Peabiru, que foi desmembrado juntamente com Campo Mourão, do município de Pitanga, os demais munícipios se desmembraram de Campo Mourão (MASSOQUIM, 2010).

Para o presente estudo, foram utilizados dados de 24 postos pluviométricos (Figura 2) para o período de 1976 a 2016. A série histórica dos dados destas estações apresenta menos de 5\% de falha nos dados. Alguns dados faltantes foram consistidos pelo próprio Instituto das Águas do Paraná. Os dados de 23 postos pluviométricos obtidos a partir do site do Instituto das Águas do Paraná, pertencentes ao Instituto das Águas do Paraná e à Agência Nacional das Águas (ANA). Outros dados de precipitação utilizados foram o da Estação Climatológica Principal de Campo Mourão, conveniada ao Instituto Nacional de Meteorologia (INMET), baixado do Banco de Dados Meteorológicos para Ensino e Pesquisa no site do INMET. Esta estação aqui será denominada apenas de INMET. 
Figura 1- Municípios da MRCM.

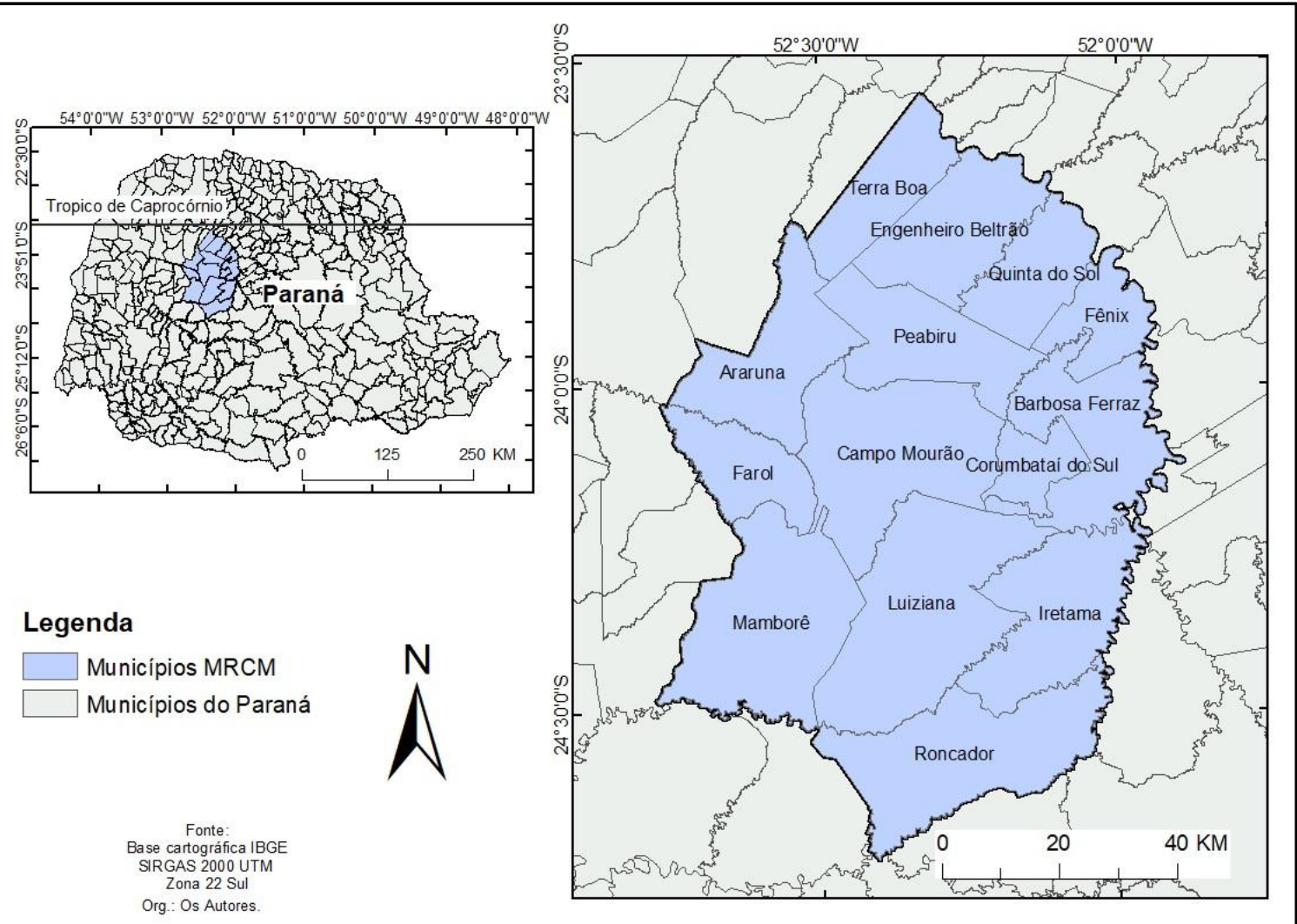

Fonte: autores.

Figura 2 - Espacialização das estações/postos pluviométricos da MRCM.

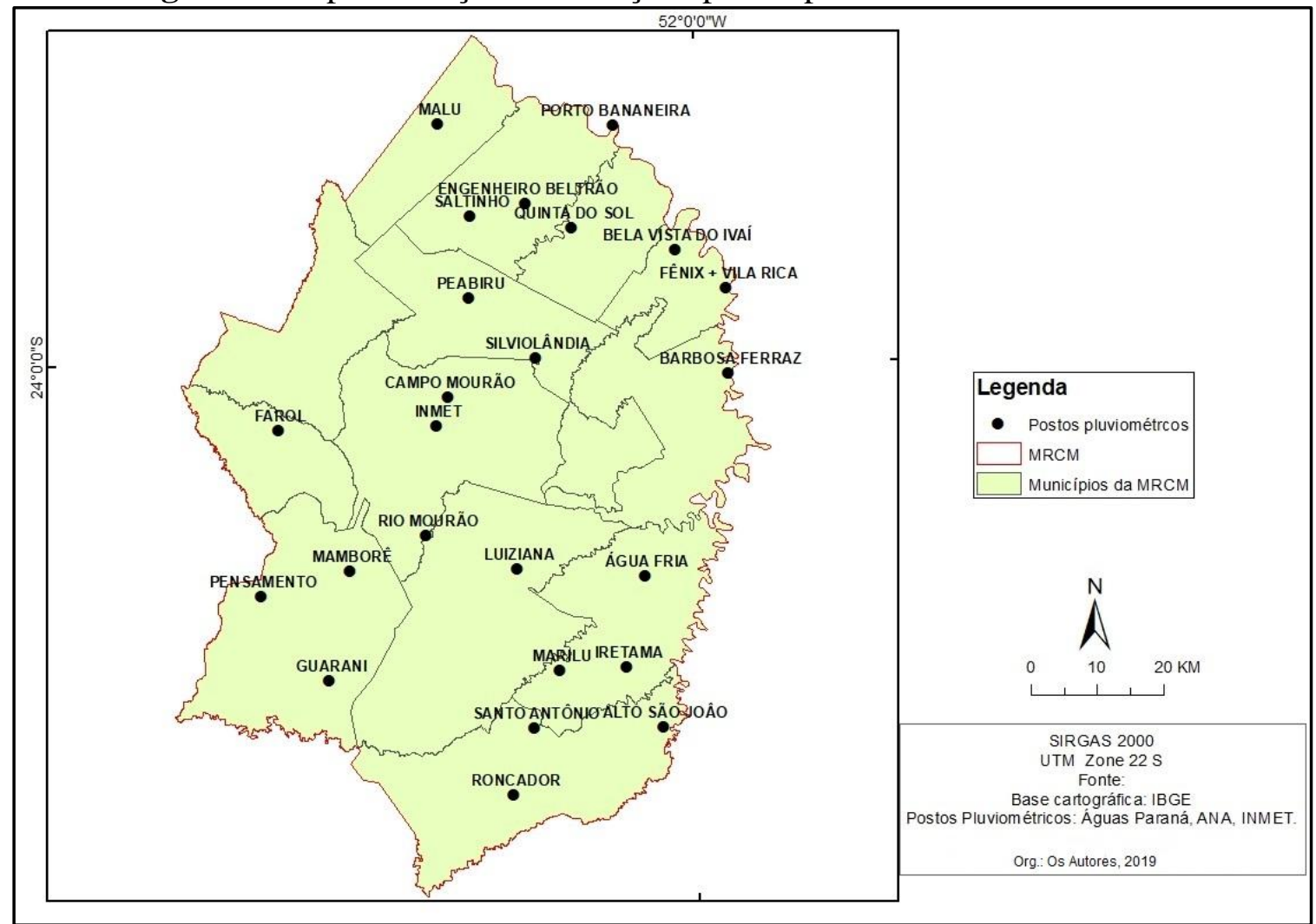

Fonte: autores. 
Para identificação de unidades espaciais homogêneas quanto à variabilidade climática foi utilizada a técnica de Cluster pelo método Ward. Esta técnica é utilizada para agrupamentos homogêneos, partindo de cálculos multivariados (RAO e SRINIVAS, 2006). Da aplicação desta técnica resultaram duas unidades espaciais homogêneas de variabilidade de precipitação para a MRCM, sendo denominadas Norte da MRCM (NMRCM) e Sul da MRCM (SMRCM). Em seguida, os dados das estações foram tabulados no software Excel, calculando-se a média mensal com os valores dos postos integrantes de cada uma das duas unidades espaciais homogêneas.

A partir destas séries de dados foram calculadas as médias pluviométricas sazonais e anuais de cada unidade espacial, as anomalias mensais, sazonais e anuais, o desvio padrão e o coeficiente de variação. A anomalia foi calculada a partir da subtração do valor total anual da precipitação do valor médio em cada região para o período de 1976 a 2016. Esses resultados foram apresentados em gráficos e tabelas. Para melhor visualização dos dados foi elaborado gráfico de box plot no software Past.

Para compreensão da espacialização da precipitação na MRCM, foi elaborado um mapa de isoieta pelo método de krigagem no software Arcgis. As isoietas foram plotadas sobre o mapa hipsométrico (base de dados Shuttle Radar Topography Mission - SRTM, obtida no site da United States Geological Survey - USGS).

\section{Resultados e discussão}

Na Figura 3, apresenta-se o mapa com a distribuição das chuvas na MRCM entre o período de 1976 a 2016. Verifica-se que os maiores totais de precipitação ocorrem em na faixa sul da mesorregião.

Para entender melhor a variabilidade espacial da chuva, exposta inicialmente na Figura 3, elaborou-se a análise de Cluster. Na Figura 4A apresenta-se o dendograma a partir do qual se identificaram as unidades espaciais homogêneas de variabilidade de precipitação a partir da aplicação da técnica de Cluster, separadas no primeiro nível de agrupamento. A Figura 4B apresenta a espacialização dos postos, sendo possível verificar que há um padrão de distribuição norte/sul. A partir da criação dessas duas unidades espaciais homogêneas, foi verificada a relação do acumulado pluviométrico anual entre elas, sendo que para a NMRCM este valor é 1654,8 mm e da SMRCM é 1866,5 mm, uma diferença de 211,7 mm. 
Figura 3 - Distribuição da chuva na MRCM durante o período de 1976 a 2016.

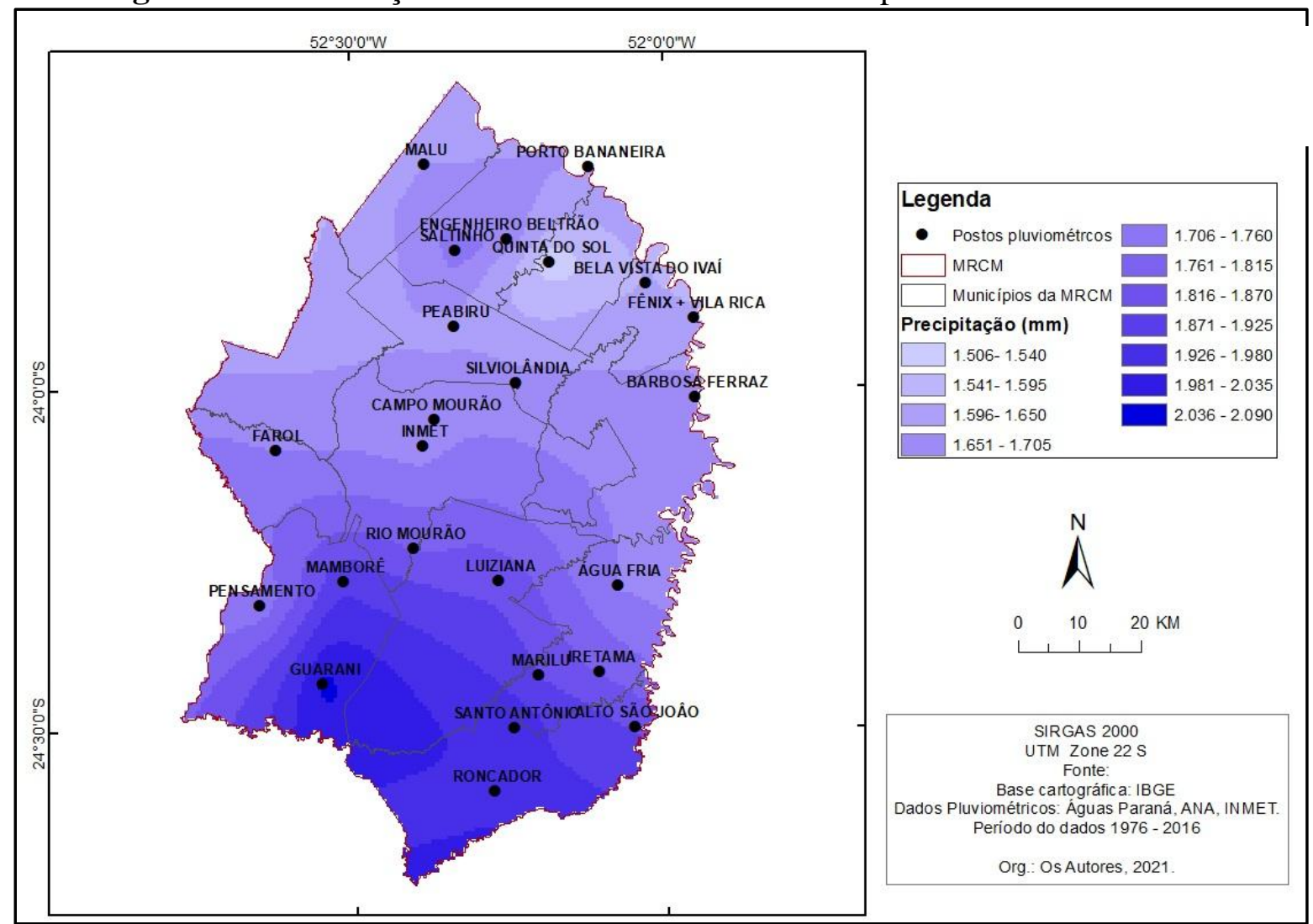

Fonte: autores.

Figura 4 - (A) Dendrograma com o resultado da aplicação da técnica de Cluster; (B) Distribuição espacial dos postos segundo as duas unidades espaciais homogêneas identificadas pela técnica de Cluster.

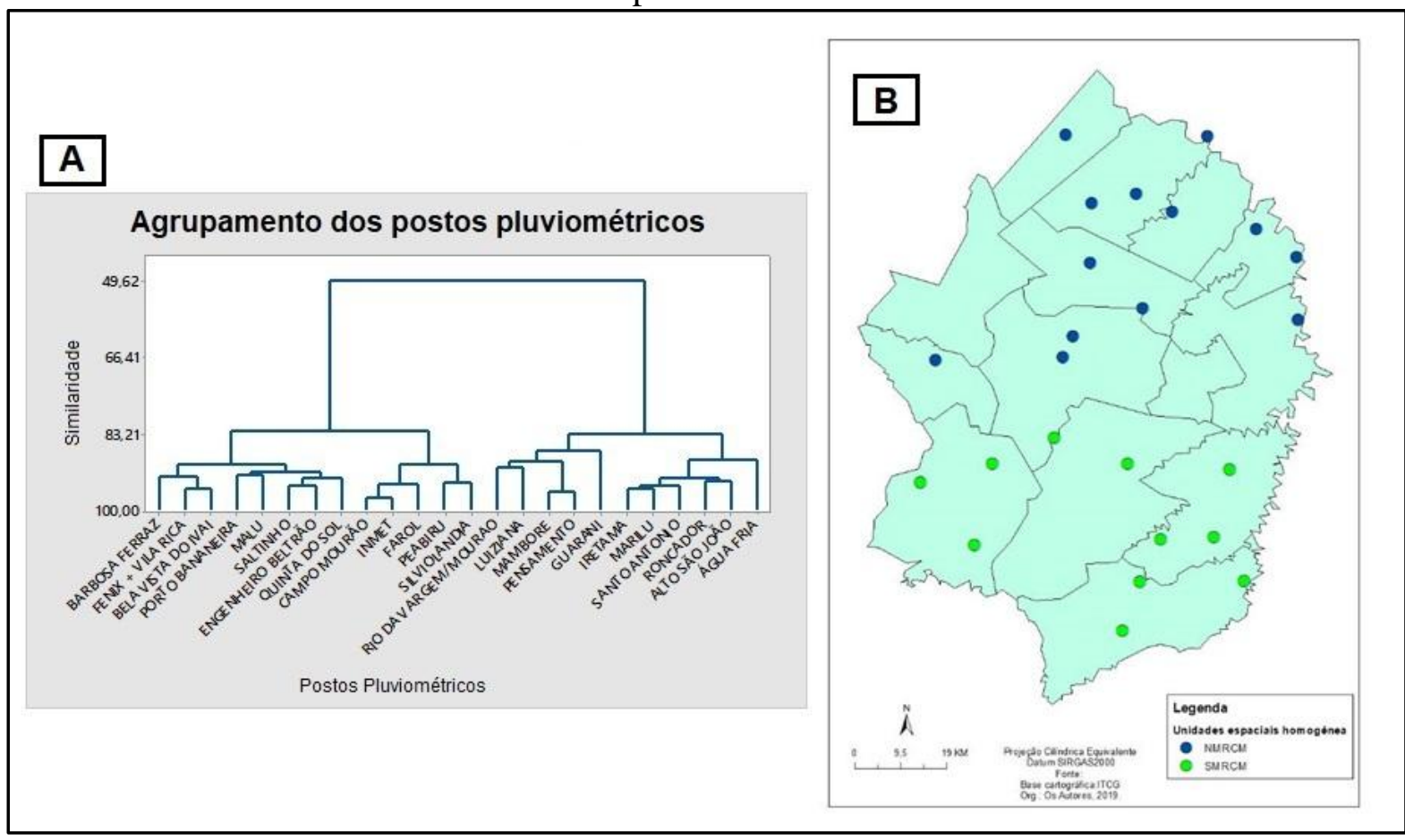

Fonte: autores. 
A partir da identificação dos dois agrupamentos na Figura 4A foi possível realizar a distribuição espacial dos postos pluviométricos (Figura 4B), sendo que o primeiro agrupamento ou NMRCM, é constituído pelos postos: Barbosa Ferraz, Fênix+Vila Rica, Bela Vista do Ivaí, Porto Bandeira, Malu, Saltinho, Engenheiro Beltrão, Quinta do Sol, Campo Mourão, INMET, Farol, Peabiru e Silviolândia; e o segundo agrupamento, ou SMRCM é constituído pelos postos: Rio da Vargem/Mourão, Luiziana, Mamborê, Pensamento, Iretama, Marilu, Santo Antônio, Roncador, Alto São João, Água Fria e Guarani.

Na figura 5, que mostra o gráfico de box plot para as duas médias, observa-se que para os $50 \%$ dos valores entre o $1^{\circ}$ e o $3^{\circ}$ quartil (a caixa cinza), os valores variam mais na NMRCM do que na SMRCM. Porém, os limites inferior e superior da SMRCM foram igualmente preenchidos, fator que a difere da NMRCM, já que o limite superior foi maior que o inferior. Isso mostra que não existe uma variação proporcional na MRCM como um todo, sendo que em anos de menor precipitação ambas as unidades espaciais possuem valores semelhantes de precipitação. Isso permite afirmar que em anos mais secos sistemas atuam de forma proporcional para reduzir a precipitação em toda a MRCM, mas isso será melhor analisado na sequência do artigo. Outro ponto interessante a ser verificado no gráfico são os outliers, sendo que o da NMRCM representa o ano de 2015 e a da SMRCM o ano de 1983. Em 1983 e 2015 ocorreram eventos de El Niño muito forte, que tem como reflexos para a região Sul do Brasil a ocorrência de precipitação acima da média climatológica (GRIMM, BARROS e DOYLE, 2000; GRIMM, 2003; 2009). Para a MRCM, de acordo com Marins e Limberger (2018), este é o principal modo de variabilidade climática.

Figura 5 - Box plot da chuva anual do NMRCM e SMRCM.

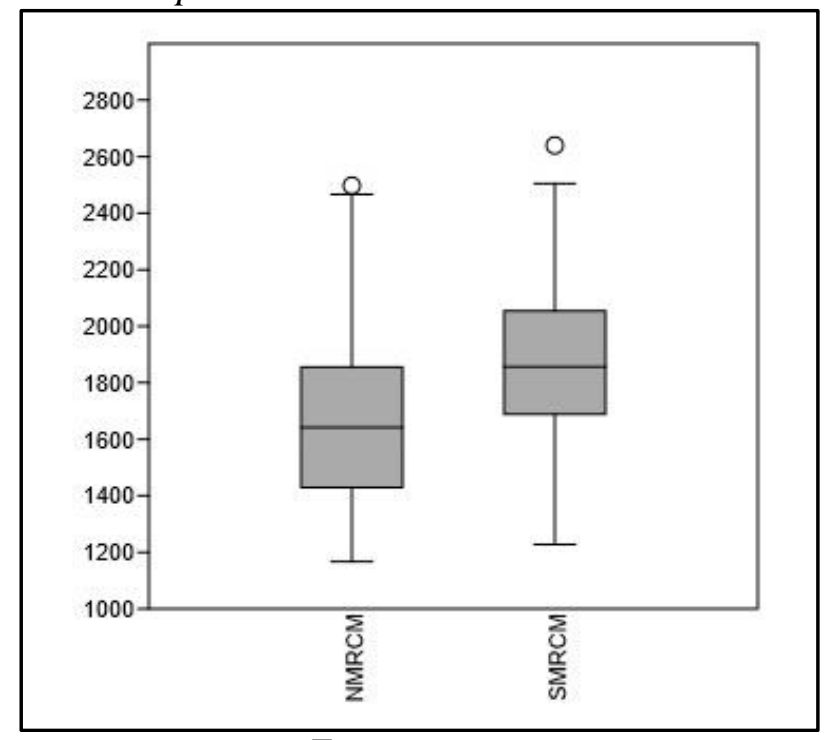

Fonte: autores. 
Ou seja, por ter ocorrido o fenômeno El Niño forte em 1983 e 2015 e ocorrerem tais diferenças espaciais, evidencia-se a própria variabilidade dos efeitos dos eventos ENOS (AMBRIZZI, 2003) e a possibilidade de que as diferenças entre as unidades espaciais podem estar atreladas a aspectos locais e/ou de sistemas atuantes.

Essa diferença nos valores entre as duas unidades espaciais aparece também na Figura 6, onde são apresentados os valores de anomalias de precipitação anual. Quanto às anomalias positivas destacam-se os anos de 1983 e 2015, quando registraram-se os maiores valores de anomalias positivas de precipitação para ambas, com $811 \mathrm{~mm}$ e $842 \mathrm{~mm}$, respectivamente, para a NMRCM e $773 \mathrm{~mm}$ e $638 \mathrm{~mm}$, respectivamente, para a SMRCM. Nos dois casos, houve maior valor de precipitação na NMRCM do que na SMRCM.

Figura 6 - Anomalia do total anual da precipitação para as unidades espaciais homogêneas NMRCM e SMRCM, para o período de 1976 a 2016.

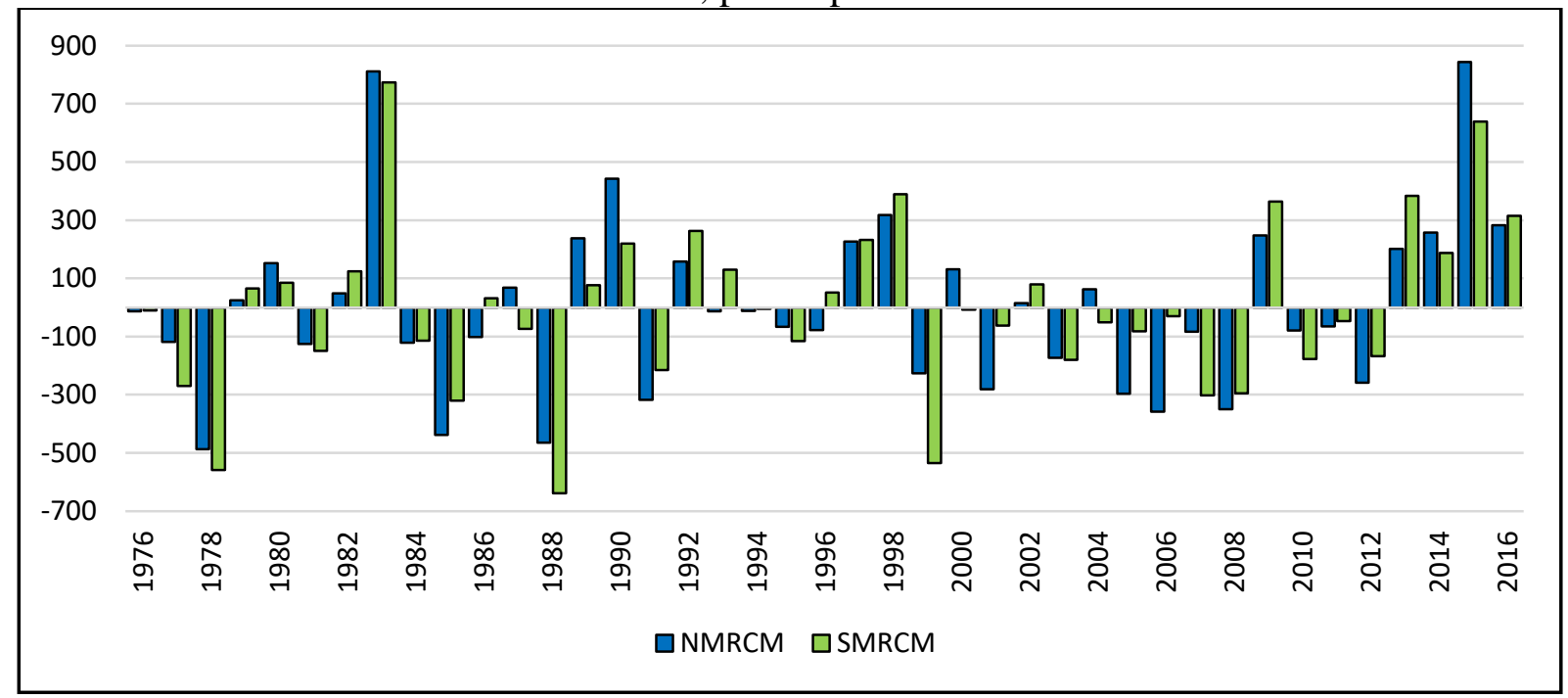

Fonte: autores.

Ressalta-se, que no ano de 1997/1998 ocorreu outro evento El Niño forte, que não causou efeitos tão importantes de anomalias de chuvas nas duas unidades espaciais em foco quanto em 1983 e 2015.

Quanto às anomalias negativas, os maiores desvios foram registrados em 1978 (-487 mm), 1988 (-464 mm) e 1985 (-437 mm) na NMRCM e 1988 (-638 mm), 1978 (-559 mm) e 1999 (-534 mm) na SMRCM. Dentre estes anos, somente em 1978 não foi registrada La Niña. Este fenômeno, oposto ao El Niño, está relacionado à redução de chuva. Identifica-se, portanto, que o El Niño/Oscilação Sul (ENOS) influencia a variabilidade climática nas duas unidades espaciais com intensidades diferentes. 
Ainda na Figura 6 é possível notar que entre 2005 a 2012 a precipitação anual foi sempre negativa com relação à média, exceto em 2009, quando ocorreu um EL Niño moderado e os valores tiveram anomalia positiva. Entre 2013 e 2016 se observa um aumento nos totais de chuva.

Para os valores médios mensais, em todos os meses há registro de mais chuva na SMRCM em comparação ao NMRCM, como pode ser visto na Figura 7.

Figura 7 - Distribuição (ciclo sazonal) da precipitação pluviométrica média mensal para o período de 1976 a 2016.

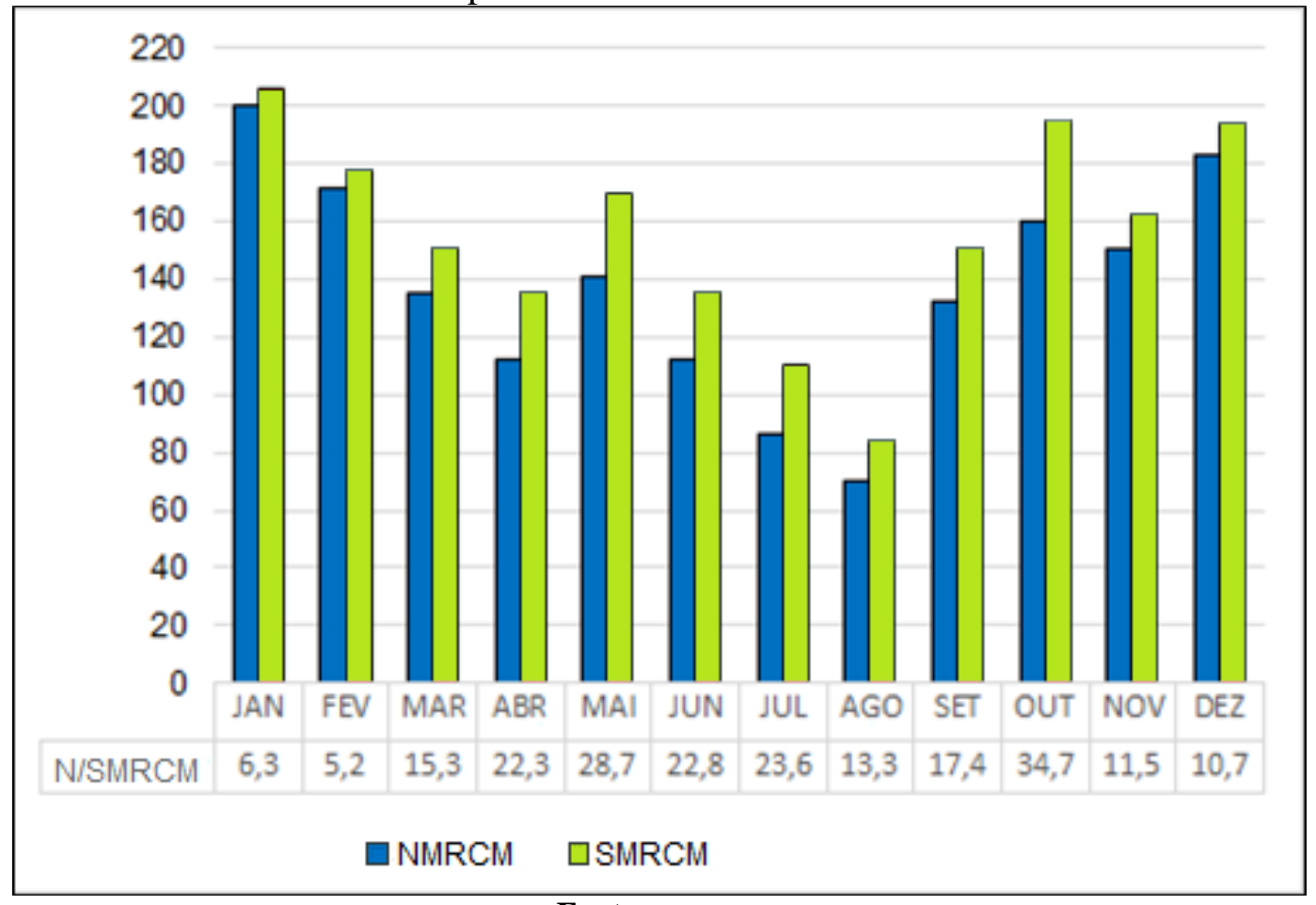

Fonte: autores.

Os meses nos quais são identificadas as maiores diferenças entre as suas sub-regiões são outubro e maio, em que na SMRCM registra-se, respectivamente, $34,7 \mathrm{~mm}$ e $28,7 \mathrm{~mm}$ a mais do que na NMRCM. Já os meses com menor diferença são janeiro e fevereiro, com diferença de $6,3 \mathrm{~mm}$ e 5,2mm, respectivamente. Na SMRCM apenas o mês de agosto registrou chuva média inferior a $100 \mathrm{~mm}$, enquanto na NMRCM isso ocorreu para os meses de julho e agosto. Em relação aos meses mais chuvosos, em ambas, o mês mais chuvoso é janeiro; porém, o segundo mais chuvoso para a SMRCM é outubro e para a NMRCM é o mês de dezembro. Esses valores mostram que a NMRCM tem padrão de distribuição da precipitação mais assemelhado com as características do clima tropical, com maiores valores de precipitação ocorrendo no verão, enquanto que o inverno é marcado por redução das mesmas. Já a SMRCM tem padrão pluviométrico mais assemelhado com o clima subtropical, com doi.org/10.48075/geoq.v14i1.22639 
chuvas melhor distribuídas durante o ano e chuvas mais intensas nos meses de transição, quando atuam sistemas tipicamente de verão e de inverno, e as diferenças térmicas permitem uma atuação de frentes frias mais intensas.

Analisando-se a distribuição da chuva na NMRCM pelo gráfico de box plot, apresentado na Figura 8A, verifica-se que para os meses de maio, janeiro e setembro há uma grande variação entre os quartis 1 a 3; já os meses com menor variação entre os quartis são abril, março e julho. Essa amplitude dos quartis mostra 50\% dos valores em torno da mediana. Os meses de maio, janeiro e setembro demonstraram também uma maior amplitude na parte superior do box plot, enquanto fevereiro mostra-se o mais proporcional entre os meses. Em relação aos outliers, o mês de junho mostra a maior quantidade de valores discrepantes e no mês de julho foi registrado o maior valor para o período de análise, ou seja, a maior variabilidade ocorre no inverno. Para os meses nos quais o $1^{\circ}$ e o $3^{\circ}$ quartil são mais amplos, como janeiro, fevereiro, maio, setembro, outubro e dezembro, não se observam outliers, o que demonstra que estes tendem a variação de valores próximo de sua média durante o período analisado (1976-2016).

Figura 8 - Gráfico de Box plot da chuva média mensal para o período de 1976 a 2016 na A) NMRCM e B) SRMCM.

A)

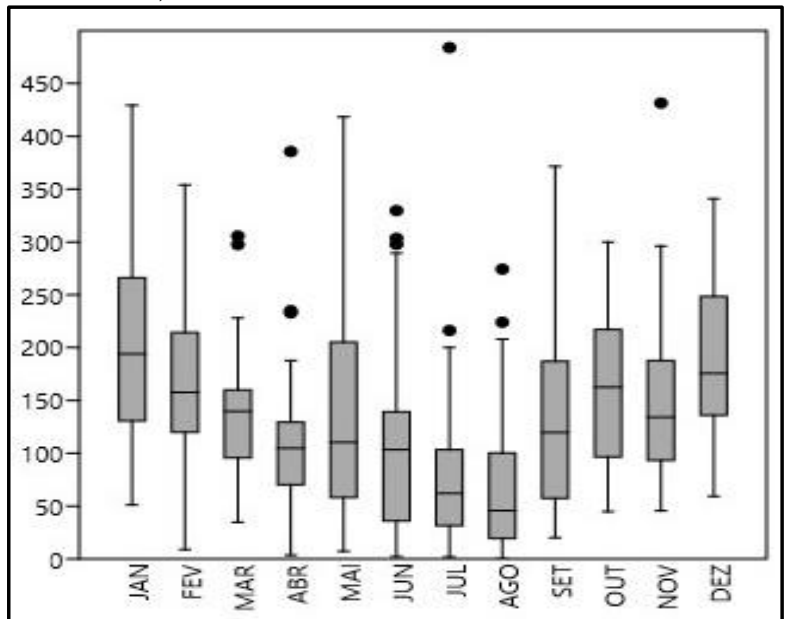

B)

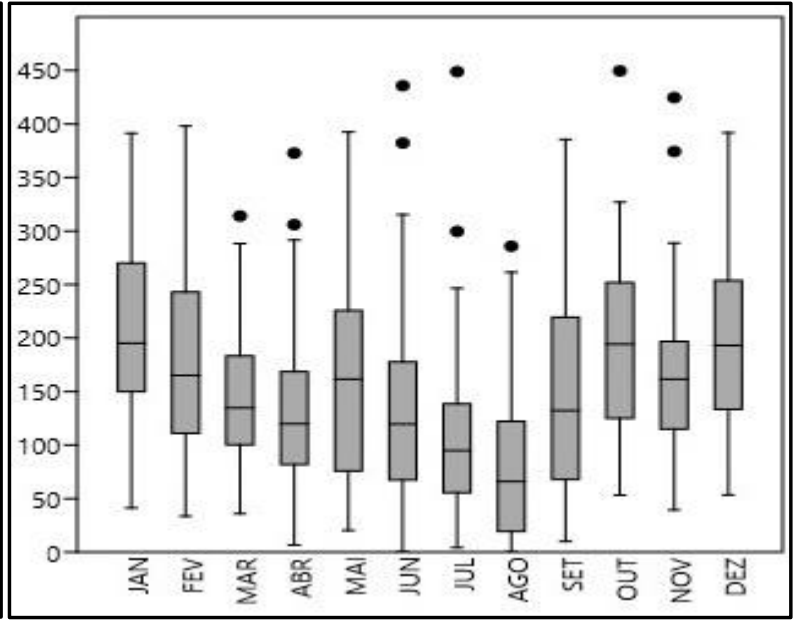

Fonte: autores.

Para a SMRCM, na Figura 8B, verifica-se que a distribuição da chuva se assemelha com a NMRCM, sendo os meses com maior variação entre o $1^{\circ}$ e $3^{\circ}$ quartil são maio, setembro e fevereiro, este sendo o diferencial com relação à NMRCM (já que nesta lista-se o mês de janeiro). Em relação aos outliers destacam-se junho e julho (como na NMRCM) e outubro. 
Ao relacionar os dois gráficos (NMRCM e SMRCM), observa-se que o SMRCM tem maior variação de precipitação, mesmo com um outlier a menos.

Ao comparar os valores sazonais (Figura 9), o verão é a estação mais chuvosa para a NMRCM (507 mm), enquanto na SMRMC os maiores valores de precipitação $(550 \mathrm{~mm})$ ocorrem na primavera. Para ambas, a estação menos chuvosa é o inverno, com $289 \mathrm{~mm}$ na NRMCM e 343 mm na SMRCM. Mais uma vez pode-se verificar que a NMRCM tem padrão climático tendendo ao tropical e a SMRCM, tendendo ao subtropical.

Figura 9 - Distribuição sazonal da precipitação pluviométrica entre 1976 -2016

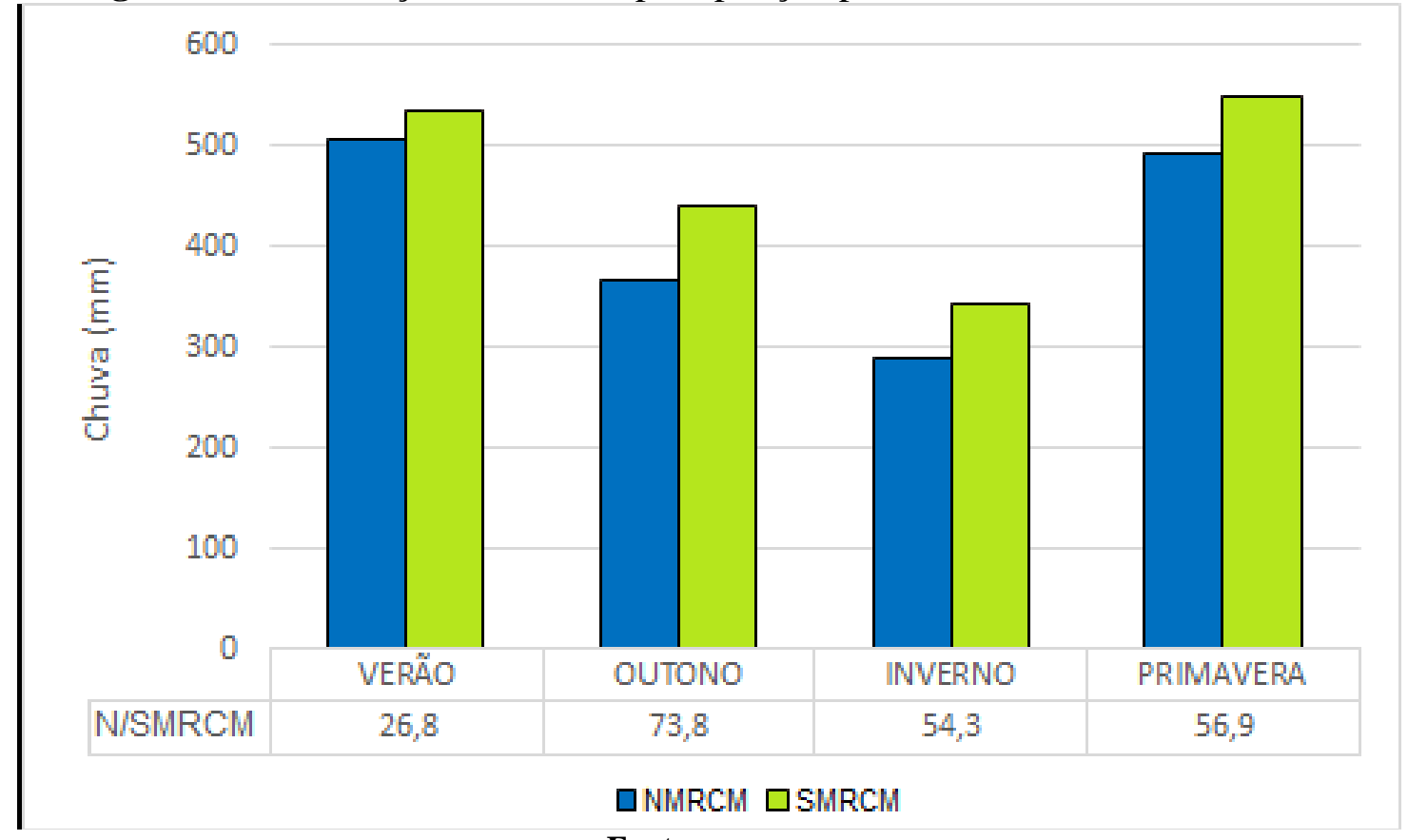

Fonte: autores.

Ainda analisando a distribuição sazonal da precipitação (Figura 9), a menor diferença entre as unidades espaciais ocorre no verão, com $26 \mathrm{~mm}$, enquanto as maiores diferenças são registradas no outono $(73,8 \mathrm{~mm})$, como pode ser visto na Figura 9. A menor diferença ocorre no verão e isso se deve ao fato de esta estação ser marcada por aporte de umidade para o continente, instabilizando a atmosfera, gerando sistemas que, associados à monção da América do Sul, afetam o norte da região Sul do Brasil produzindo chuvas (GRIMM, 2009). Durante o inverno a maior convergência de umidade está localizada mais ao sul da Região Sul do Brasil, bem como, as condições da atmosfera permitem a frontogênese, que afetaria mais a SMRCM, fazendo com que durante os meses mais frios do ano houvesse maior diferença de precipitação entre as duas unidades espaciais em análise (GRIMM, 2009). 
Tanto para os dados mensais quanto sazonais é interessante destacar o padrão espacial identificado, com os maiores valores de precipitação sendo registrados na região SMRCM. Outro ponto a ser destacado é que, apesar de a distribuição da precipitação na NMRCM ser típica do clima tropical (com maiores valores no verão e menores no inverno), na SMRCM tal distribuição é menos característica, por ser uma região de transição climática (GRIMM, 2009).

Esta diferenciação espacial na variabilidade pluviométrica em Norte/Sul na MRCM já foi verificada em outras pesquisas, tais como, Baldo (2006), Freire (2014) e Borsato (2013).

Baldo (2006) afirma que a chuva nesta região está associada ao relevo, já que na passagem dos sistemas frontais a área com relevos mais elevados tende a receber mais chuva que em área de relevo mais baixo, pois as áreas mais altas facilitam maior convecção do ar (boa parte da chuva nessa área são provocadas por sistemas transientes, como os frontais) (BORSATO, 2006; BALDO, 2006). Pode-se dizer que as regiões preferencialmente com maior volume pluviométrico se tornam áreas que ficam a montantes de bacias hidrográficas. A maior parte da MRCM está inserida na bacia do rio Ivaí, precisamente na margem esquerda.

Algo parecido identificou Borsato (2013) ao analisar a variabilidade pluviométrica e a produtividade agrícola da Mesorregião Centro Ocidental Paranaense, Mesorregião em que a MRCM está inserida, com dados de 1976 a 2011. Neste trabalho identificou-se que as regiões à montante das bacias dos rios Ivaí e Piquiri registram uma variabilidade pluviométrica diferente do que a registrada à jusante da bacia. De acordo com a autora, isso estaria relacionado aos aspectos da transição climática, e, sobretudo ao relevo que, relacionado aos sistemas frontais, favoreceria chuvas do tipo orográfica nas regiões de maior altitude.

Freire (2014), ao analisar os dados pluviométricos para o período de 1980 a 2012 da bacia do rio Mourão (que está inserida na MRCM, ocupando 23,3\% da sua área), identificou duas áreas homogêneas quanto à variabilidade da pluviometria, distinguindo-se na porção à montante da bacia e na porção à jusante da bacia. De acordo com o autor, a diferença entre estas áreas se deve a dois principais fatores: orografia e faixa de transição climática, evidenciado pelo fato de que à jusante da bacia o relevo é mais baixo e está mais próximo ao Trópico de Capricórnio, sob efeito do clima tropical. Já, a área à montante se caracteriza por relevos mais elevados, o que favorece a precipitação, e está sob influência do clima subtropical úmido, que o leva a ser mais chuvoso. 
Para melhor entendimento da relação chuva e relevo na MRCM, apresenta-se a Figura 10, onde se identifica que, para as 24 estações analisadas, existe uma relação entre a altitude e a pluviometria (média anual para o período de 1976-2016) de cada estação, com valor de r=0,694. Ou seja, nos postos pluviométricos localizados em áreas mais elevadas, há valores médios maiores de total anual de precipitação. Há uma diferença de $504 \mathrm{~m}$ entre o posto localizado na menor altitude (Quinta do Sol, com $315 \mathrm{~m}$ de altitude) e na maior altitude (Alto São João, com 819 m). Essa diferença é significativa para a produção de chuva já que o relevo favorece maior levantamento de ar e seu resfriamento adiabático, provocando maior convecção e precipitação local (BARRY e CHORLEY, 2013).

Figura 10 - Relação altitude e chuva das estações componentes da MRCM.

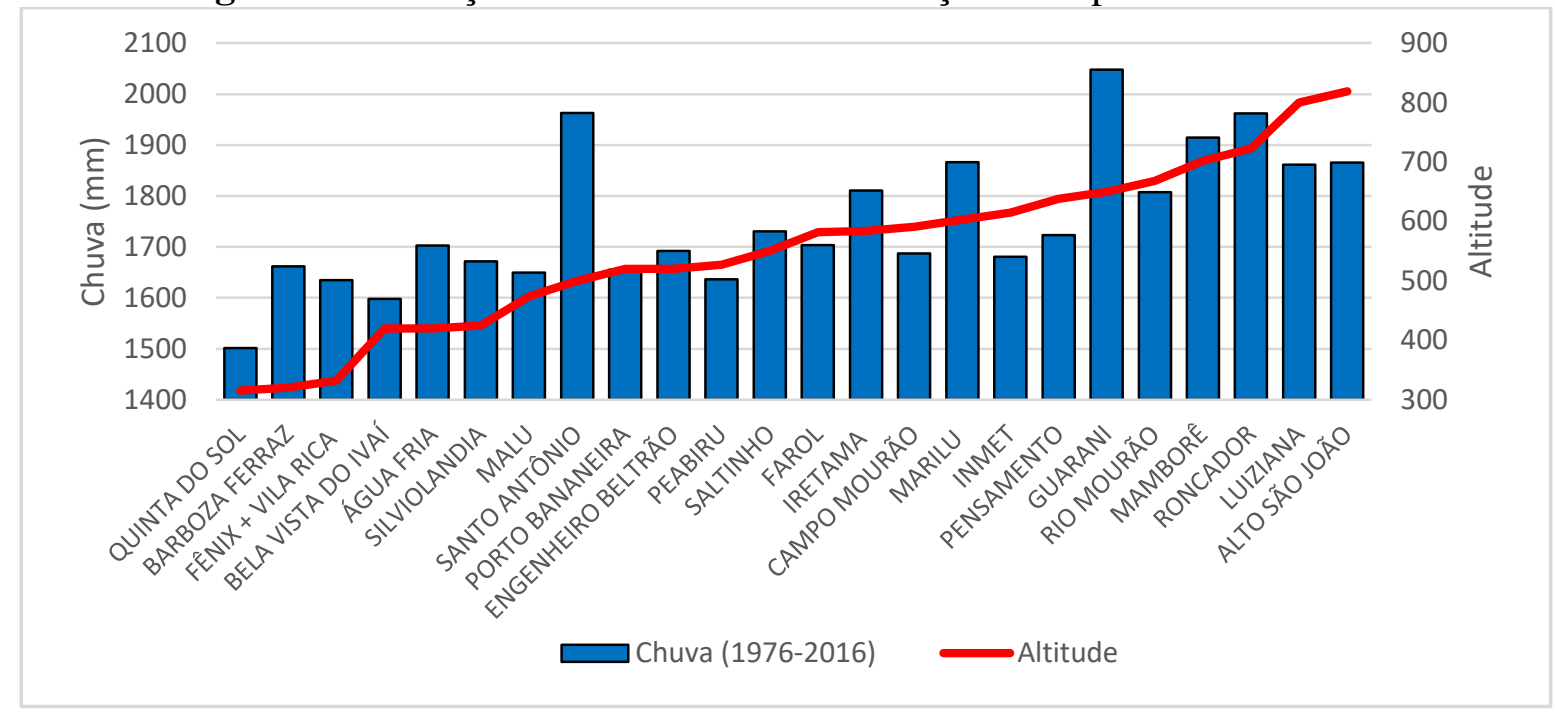

Fonte: autores.

Com intuito de melhor compreensão da relação entre altitude e valores totais anuais de precipitação foi elaborada a Figura 11, onde é possível ver plotadas as isoietas sobrepostas ao mapa hipsométrico da MRCM. Na porção ao sul se observa uma pequena barreira orográfica, e subtende-se que sistemas de chuva provenientes de sul, como os frontais, sofrem influência local do relevo, já que os maiores valores de precipitação estão à barlavento da direção predominante dos sistemas frontais, que é de sudoeste para nordeste. A precipitação vai diminuindo de acordo com a diminuição da altitude, que, coincidentemente, acompanha a direção norte. 
Figura 11 - Mapa de Isoieta sobrepondo o mapa de hipsométrico da MRCM.

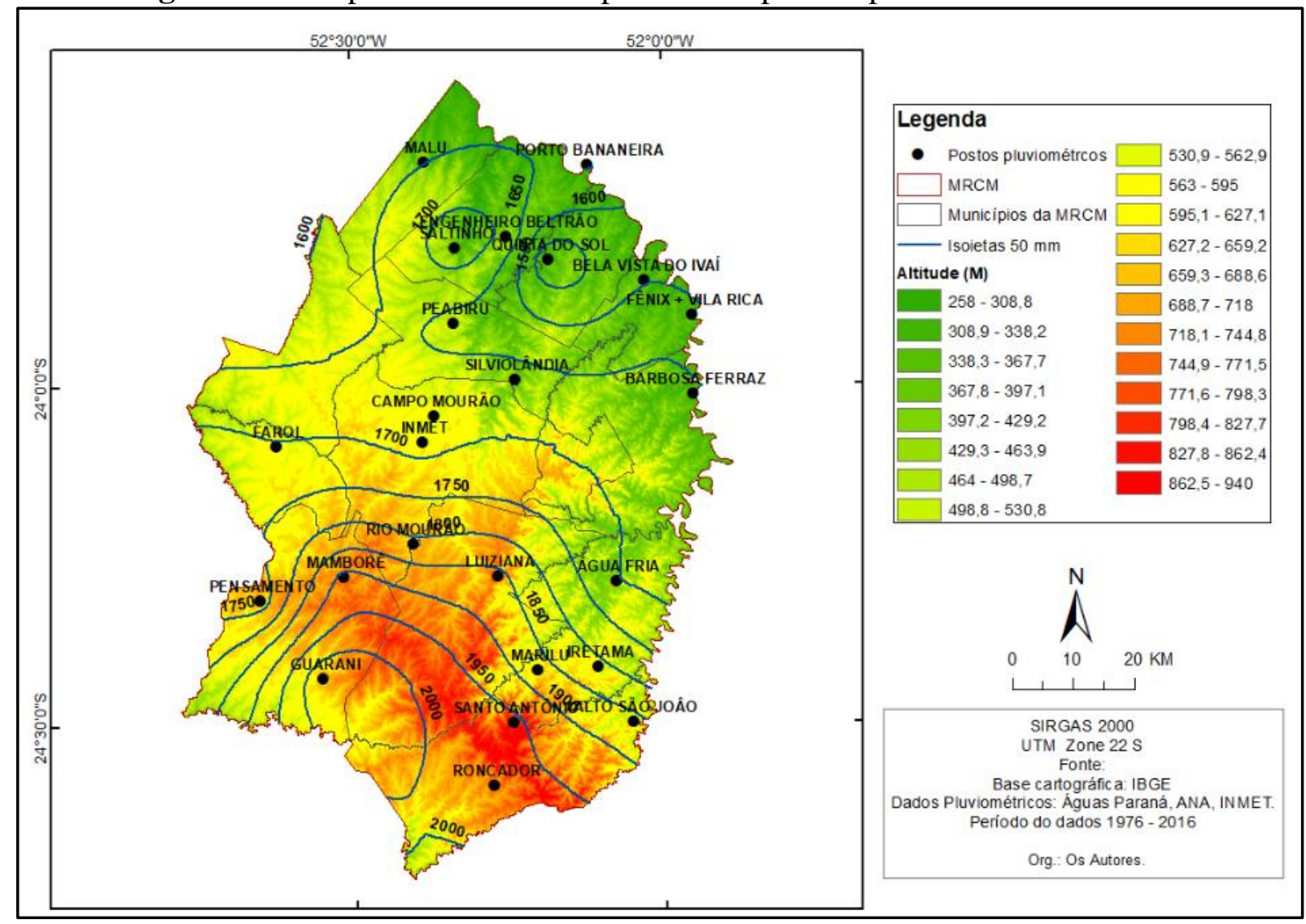

Fonte: autores.

Para verificar também a relação latitude e valores totais anuais de chuva, analisa-se a Figura 12. É possível identificar que quanto maior a latitude, ou seja, mais próximo do core do clima subtropical, é maior o valor da precipitação total anual.

Figura 12 - Relação latitude e chuva das estações

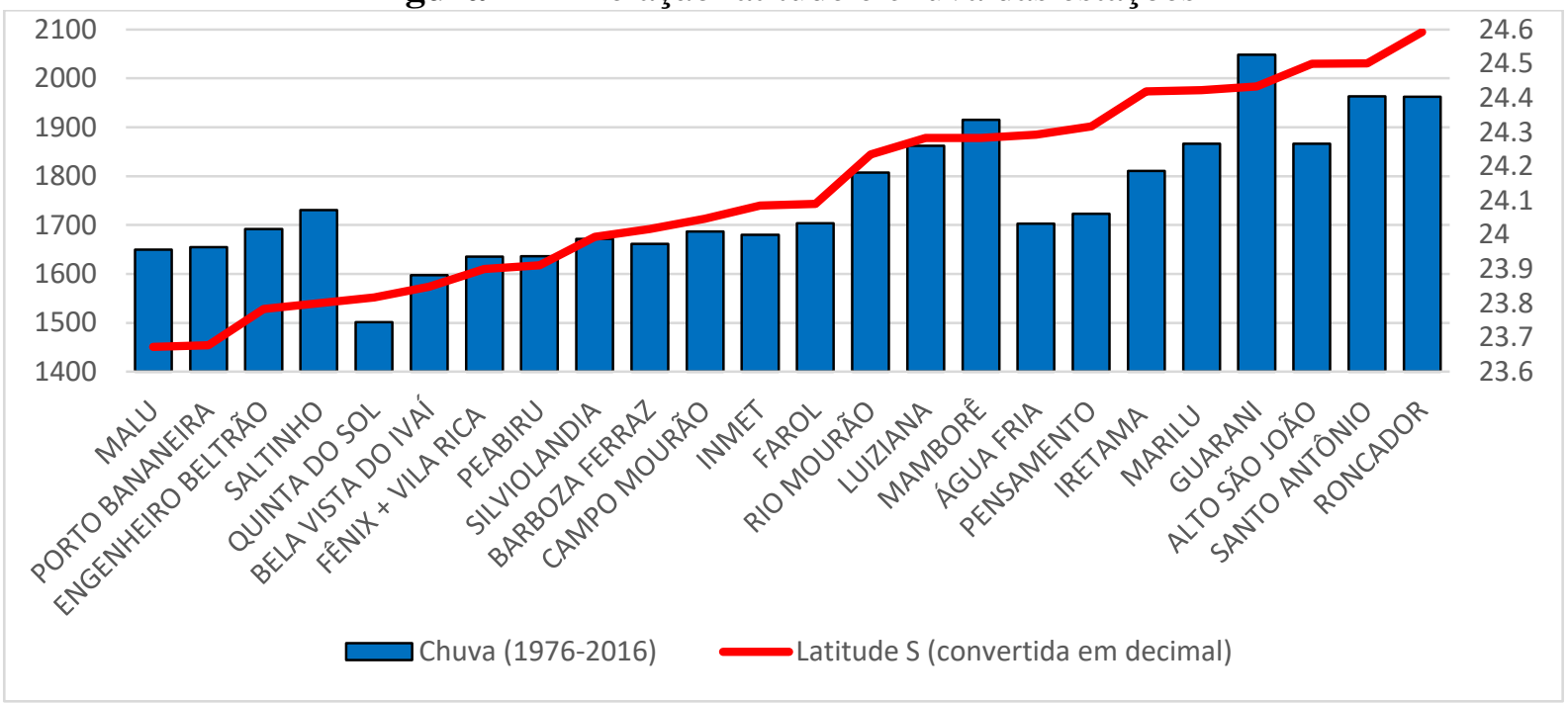

Fonte: autores. 
Como podemos ver na Figura 12, nos postos pluviométricos mais ao sul da MRCM o valor de precipitação é superior ao da área ao norte, como já mostrado nos dados anteriores desta pesquisa. A correlação linear entre precipitação e latitude na MRCM é r=0,798, maior, portanto, que a correlação com a altitude. No entanto, é impossível separar o que seria a influência da latitude ou da altitude, já que as duas características se complementam para direcionar a variabilidade espacial da chuva na MRCM.

$\mathrm{O}$ fator latitude explicaria as diferenças transicionais entre os climas Tropical e Subtropical. Além disso, dependendo da latitude, os sistemas de tempo atingem a MRCM de forma diferenciada.

Os principais sistemas atmosféricos que atuam na região são os frontais, que atingem inicialmente a porção sul e, auxiliados pelo relevo, podem favorecer a maior quantidade de chuvas. Porém, para além dos sistemas frontais, atuam na área os SCMs e sistemas de baixa pressão provenientes de regiões: norte da Argentina e Paraguai, e linhas de instabilidade préfrontal, (REBOITA et al., 2012). Em alguns casos, na medida em que tais perturbações atmosféricas de deslocam, elas perdem umidade. Em alguns casos, principalmente os associados ao fluxo dos jatos de baixos níveis (JBNs), sobretudo os provenientes do norte da AS, tendem a manter o fluxo de umidade, mesmo na passagem por áreas mais elevadas. As influências dos JBNs provenientes da Amazônia ocorrem preferencialmente durante o verão, já no inverno a umidade é proveniente do Atlântico Sul (GRIMM, 2009; MARENGO, AMBRIZZI e SOARES, 2009).

Portanto, os elementos climáticos que tem papel proporcionador da variabilidade espacial na MRCM são altitude e latitude. Isso sugere que o que determina o padrão de distribuição espacial da chuva ao longo do tempo são os sistemas atmosféricos que atuam na área, diferenciados pelo fator altitude.

Nesse sentido, identifica-se que a MRCM pode ser dividida em uma área com clima mais próximo do subtropical, a sua faixa sul, ou SMRCM, como definido dessa pesquisa. Essa área tem chuva melhor distribuída durante o ano, o que favorece seus maiores valores totais anuais. Já a NMRCM tem padrão climático mais próximo do tropical típico, com maior redução de chuvas no inverno e valores mais expressivos no verão. 


\section{Considerações Finais}

O presente artigo analisou a variabilidade espacial da precipitaçao na MRCM. A análise de cluster identificou duas unidades espaciais, denominadas SMRCM e NMRCM, com padrões de variabilidade diferentes entre si.

Análises das médias dos postos meteorológicos que compõem cada uma das subregiões indicaram que, em ambas, as anomalias positivas e negativas de precipitação anual são associadas com ENOS. No entanto, o presente estudo não analisou outros eventos que causam variabilidade climática, o que indica para estudos futuros.

Identificou-se, pela análise do ciclo sazonal médio, que a NMRCM tem comportamento que se assemelha ao de clima tropical, com maior redução das chuvas nos meses de inverno. Na SMRCM essa redução das chuvas nos meses de inverno é menos expressiva, o que a aproxima de um comportamento de clima subtropical, onde a precipitação é bem distribuída durante o ano. Essa constatação é importante no contexto do presente artigo, já que reforça a ideia de variabilidade espacial da precipitação na MRCM, localizando-se em uma área de transição climática.

Outras diferenças foram identificadas entre as sub-regiões SMRCM e NMRCM. A disposição dos valores mensais em box plot indicam que a SMRCM apresenta mais eventos que se distanciam dos valores médios do que a NMRCM.

Os dados também indicam que há diferenças sazonais entre as duas unidades espaciais. A estação mais chuvosa na SMRCM é a primavera, enquanto na NMRCM os maiores valores de precipitação ocorrem no verão. A estação menos chuvosa em ambas é o inverno.

Os testes realizados com dados de latitude e altitude dos postos meteorológicos indicaram que, quanto mais elevada for a estação meteorológica, maiores são os valores de precipitação, assim como, quanto maiores as latitudes, maiores também serãos os índices pluviométricos. Apesar de os valores de correlação linear terem sido maiores para latitude $(\mathrm{r}=0,7968)$ do que para altitude $(\mathrm{r}=0,694)$, é preciso considerar que as maiores altitudes estão na faixa sul da MRCM, o que dificulta a definição de qual desses fatores é o responsável pela variabilidade espacial na MRCM.

A altitude favorece maior precipitação já que favorece a convecção de ar. No entanto, diferentes sistemas atmosféricos atuam sobre a MRCM, já caracterizada como área de transição climática. Os sistemas atmosféricos que atuam na faixa sul favorecem maior 
precipitação nas estações de transição e no inverno, quando são registradas as maiores diferenças quanto à NRMCM. Com isso, os valores de precipitação são maiores da SMRCM.

Assim, tanto altitude quanto latitude parecem explicar a variabilidade espacial da chuva na MRCM; a latitude, pois a MRMC está relacionada em zona de transição, diferenciando os sistemas atmosféricos que podem atuar interanualmente, e a altitude, pois as áreas mais altas estão localizadas no sul da MRCM, favorecendo maior convecção para os sistemas atmosféricos que atuam na região.

\section{Agradecimento}

O presente trabalho foi realizado com apoio da Coordenação de Aperfeiçoamento de Pessoal de Nível Superior -Brasil (CAPES) - Código de Financiamento 001.

\section{Referências}

AYOADE, J. Introdução à climatologia para os trópicos. $5^{\circ}$ ed. Rio de Janeiro: Bertrand, 1998.

ALMEIDA, I. R. de. Variabilidade pluviométrica interanual e produção de soja no Estado do Paraná. Presidente Prudente: UNESP/FCT, 2000. 200f. (Dissertação, Mestrado em Geografia).

AMBRIZZI, T. El Niño/Oscilação Sul e suas teleconexões atmosféricas no hemisfério austral. São Paulo: USP/IAG, 2003. (Tese de Livre Docência).

BALDO, M. C. Variabilidade pluviométrica e a dinâmica atmosférica na bacia hidrográfica do rio Ivaí-PR. Presidente Prudente: UNESP/FCT, 2006. 153 f. (Tese, Doutorado em Geografia).

BARRY, R. G.; CHORLEY, R. J. Atmosfera, tempo e clima. $9^{\circ}$ ed. Porto Alegre: Bookman, 2013.

BORSATO, F. P. Variabilidade Pluviométrica e Produção Agrícola na Mesorregião Centro Ocidental Paranaense. Londrina: UEL, 2013. (Dissertação, Mestrado em Geografia)

BORSATO, V. A. A participação dos sistemas atmosféricos atuantes na bacia do Alto Rio Paraná no período de 1980 a 2003. Maringá: UEM/NUPÉLIA, 2006. (Tese, Doutorado em Ciências Ambientais). 
EM

QUESTÃO

pág. 160-179

BORSATO, V. da A.; MENDONÇA, F. de A. A Dinâmica dos sistemas atmosféricos no verão 2012-2013 no Paraná e em Campo Mourão. Simpósio de Estudos Urbanos: a dinâmica das cidades e a produção do espaço, v. 2, p. 1-30, 2013.

ELY, D. F. Teoria e método da climatologia geográfica brasileira: uma abordagem sobre seus discursos e práticas. Presidente Prudente: UNESP/FCT, 2006. 208 f. (Tese, Doutorado em Geografia).

FREIRE, V. H. N. Análise da variabilidade espaço-temporal da precipitação pluviométrica na bacia do rio Mourão - PR. Campo Mourão: UTFPR, 2014, (Graduação, Trabalho de conclusão de curso em Engenharia Ambiental).

GRIMM, A. M. The El Niño impact on the summer monsoon in Brazil: regional processes versus remote influences. Journal of Climate, v. 16, n. 2, p. 263-280, 2003.

Clima da Região Sul do Brasil. In: CAVAlCANTI, I. F. D. A.; AL., E. Tempo e Clima no Brasi. 1. ed. São Paulo: Oficina de Texto, v. 1, 2009 . Cap. 17, p. 259-275

; BARROS, V. R.; DOYLE, M. E. Climate variability in southern South America associated with El Niño and La Niña events. Journal of climate, v. 13, n. 1, p. 35-58, 2000.

MARENGO, J. A.; AMBRIZZI, T.; SOARES, W. R. Jato de Baixos Níveis ao longo dos Andes. Tempo e Clima no Brasil. Oficina de Textos, São Paulo, p. 169-180, 2009.

MARINS, J. A. L.; LIMBERGER, L. Correlação linear entre índices climáticos e a chuva na microrregião de Campo Mourão-PR, 13., 2018, Juiz de Fora, Anais ... Juiz de Fora: SBCG, 2018.

MASSOQUIM, N. G. Clima e Paisagem na Mesorregião Centro Ocidental Paranaense. São Paulo: USP/FFLCH, 2010. 398 f. (Tese, Doutorado em Ciências: Geografia Física).

MINAKI, C.; MONTANHER, O. Cr. Influência do El Niño-Oscilação Sul na precipitação em Maringá-PR, no período de 1980 a 2016. Caminhos de Geografia, v. 20, n. 69, p. 266-281, 2019.

NASCIMENTO JÚNIOR, L. As chuvas no Paraná: variabilidade, teleconexões e impactos de eventos extremos. Presidente Prudente: UNESP/FCT, 2013. 162p. (Dissertação, Mestrado em Geografia).

NERY, J. T.; VARGAS, W. M.; MARTINS, M. L. O. F. Variabilidade interanual da precipitação do Paraná. Revista Brasileira de Agrometeorologia, v. 5, n. 1, p. 115-125, 1997.

PRELA, A. Influência dos fenômenos El Niño/La Niña na produtividade de trigo no estado do Paraná. Piracicaba: USP/ESALQ, 2004, 52p. (Tese, Doutorado em Agronomia: Física do Ambiente Agrícola).

REBOITA, M. S. et al. Regimes de precipitação na América do Sul: uma revisão bibliográfica. Revista Brasileira de Meteorologia, v. 25, n. 2, 2010. 
REBOITA M.S. et al. Entendendo o Tempo e o Clima na América do Sul. Terra e Didática, 8(1):34-50. 2012.

RAO, A.R.; SRINIVAS, V.V. Regionalization of watersheds by fuzzy cluster analysis, Journal of Hydrology. 318, p.57-79. 2006.

SOUZA, P. Estudo da variabilidade da precipitação no estado do Paraná associado à anomalia da TSM no oceano Pacífico. Maringá: UEM, 2006. 72 f. (Dissertação, mestrado em Geografia).

TAVARES, A. C. Variabilidade e Mudanças Climáticas. Rio Claro: UNESP/DGEO, 2001. 228 f. (Tese, Livre-Docência). 